\title{
Found in transition: Applying milestones to three unique discharge curricula
}

Lauren Meade, Christine Y Todd, Meghan M Walsh

Introduction: A safe and effective transition from hospital to post acute care is a complex and important physician competency. Milestones and Entrustable Professional Activities (EPA) form the new educational rubric in Graduate Medical Education Training. "A safe and effective discharge from the hospital" is an EPA ripe for educational innovation. Methods: The authors collaborated in a qualitative process called mapping to define 22 of 142 Internal Medicine (IM) curricular milestones related to the transition of care. Fifty-five participant units at an Association for Program Directors in Internal Medicine (APDIM) workshop prioritized the milestones, using a validated ranking process called Q-sort. We analyzed the Q-sort results, which rank the milestones in order of priority. We then applied this ranking to three innovative models of training IM residents in the transitions of care: Simulation (S), Discharge Clinic Feedback (DCF) and TRACER $(T)$. Results: We collected 55 Q-sort rankings from particpants at the APDIM workshop. We then identified which milestones are a focus of the three innovative models of training in the transition of care: Simulation $=5$ of 22 milestones, Discharge Clinic Feedback $=9$ of 22 milestones, and TRACER $=7$ of 22 milestones. Milestones identified in each innovation related to one of the top 8 prioritized milestones $75 \%$ of the time; thus, more frequently than the milestones with lower priority. Two milestones are shared by all three curricula: Utilize patient-centered education and Ensure succinct written communication. Two other milestones are shared by two curricula: Manage and coordinate care transitions across multiple delivery systems and Customize care in the context of the patient's preferences. If you combine the three innovations, all of the top 8 milestones are included. Discussion: The milestones give us a context to share individual innovations and to compare and contrast using a standardized frame. We demonstrate that the three unique discharge curricula in aggregate capture all of the highest prioritized milestones for this discharge EPA. 
3 Found in transition: Applying milestones to three unique discharge curricula

4

5 Lauren B Meade, Christine Y Todd and Meghan M Walsh

6

7 Corresponding Author:

8 Lauren B Meade MD FACP

9 Director of Faculty Development for Medicine

10 Associate Program Director

11 Baystate Tufts Medical Center

12759 Chestnut Street

13 Springfield MA 01199

14 T 413.794.4143

15 F 413.794.8075

16 Email: Lauren.meade@bhs.org

17 Admin Assistant email: Amanda.Duda@baystatehealth.org

18

19

20 Lauren B Meade

21

22 Christine Y Todd MD

23 Chairman, Department of Medical Humanities

24 Southern Illinois University

25701 North $1^{\text {st }}$ Street

26 Springfield, IL 62781

$\begin{array}{ll}27 & 217.545 .0000\end{array}$

28 Email: ctodd@siumed.edu

29

30

31 Meghan M Walsh MD

32 Chief Medical Education Officer

33 Program Director, Transitional Residency Program

34 Hennepin County Medical Center

35701 Park Avenue

36 Minneapolis, MN 55415

37 Email: meghan.walsh@hcmed.org

38

39

40 
41 Found in transition: Applying milestones to three unique discharge training curricula

\section{Introduction:}

44

45

46

47

48

49

50 51 2004).

52

53

54

55

56

57

58

59

60

61

62

63

64

The ability to safely and effectively manage transitions of care represents a critical new

competency for today's internist. Brought to light by the increasingly prevalent separation between inpatient and outpatient services, the medical literature continues to demonstrate that poorly managed transitions of care result in significant medical errors, decreased patient satisfaction, and poor patient outcomes (Jenchks 2009; van Wlraven 2002; Kripalani 2007; Forster 2003). Coleman et al. describe the fragmentation of care in a landmark paper with the ominous title, "Lost in Transition" (Coleman

While practicing internists attempt to master their own transfer of care skills, the academic medical community is challenged by the need to identify and incorporate these skills into an effective transition of care curriculum for trainees. Discharging patients from the hospital, a major transition of care event, is a daily occurrence in the lives of Internal Medicine house-staff, yet medical literature guiding the training, supervision, and evaluation of this critical event is limited. Several studies have highlighted innovative curriculum surrounding transitions of care. Self-audits of resident discharge summaries (Dinescu 2011; Talwalkar 2012) and feedback about the discharge summary (Myers 2006; Legault 2012) improved discharge summary targets. A discharge "time out" (Coit 2010) and reduced house-staff workload also improved discharge summaries (Mohta 2012). A web-based module utilizing a well-designed teaching case emphasized the importance of communication in the transition (Eskildsen 2010). A qualitative study of the resident perspective on the interdisciplinary nature of teamwork revealed "learning by doing" as the foremost theme in two residency programs (Greysen 2012). A medical student curriculum using experiential learning that follows a patient through the 
65 transition improved confidence (Lai 2008) and was found to be both feasible and effective (Bray-Hall 66 2010).

68

Beyond the challenge of developing a program for training physicians in a new patient care venue, academic internists are facing increasingly rigorous standards for measureable training outcomes. Milestones and Entrustable Professional Activities (EPAs) are an evolving framework for defining the competence of medical trainees. Milestones are discrete observable behaviors that demonstrate competence (Green 2009). An EPA is an activity that constitutes the mass of critical elements or knowledge, skills, and attitudes (KSAs) that operationally define a profession (Ten Cate 2007; Hauer, 2014). The theory of milestones and EPAs have been well described and are beginning to be adopted as best practice goals for Internal Medicine (IM) residency programs, but there are few examples in the medical literature illustrating how to effectively turn this educational theory into practice (Nasca 2012; Schmacher 2013).

The KSAs needed to accomplish a high quality discharge are both complex and challenging, thus ripe for the application of this new paradigm of milestones and EPAs. The authors of this report created three unique curricula in transitions of care training of medical resident in their separate institutions prior to 2009, in other words, prior to the publication of the curricular milestones (Green 2009). With a call for using milestones for standard setting, we embarked on a standard-setting process for applying milestones to our three transitions of care curricula across institutions.

In 2011, the authors presented an Association for Program Directors of Internal Medicine

(APDIM) workshop on the transition of care (Meade 2011) both to describe the individual transitions of care at our institutions and to discuss and collect data on workshop participants' prioritization of milestones for transitions of care and specifically the EPA, "A safe and effective discharge from the hospital." After analyzing the Q-sort data, we reflected on our original curricula, using the prioritized milestones as a gold standard to compare and contrast our transition of care program curriculum. This 
report describes three curricula in the transition of care, the results of the group Q-sort, and the application of the prioritized milestones back to the curricula as a way to compare and contrast curriculum in for training in an EPA.

\section{Methods:}

\section{Mapping Milestones}

The authors collaborated in a qualitative process called mapping, to develop a Q-sort exercise for workshop participants related to the EPA, "A safe and effective discharge from the hospital." First, we individually choose 22 milestones of the 142 curricular milestonesthat applied to the EPA. Then, over three months, we discussed and deliberated our choices in the group process, in three rounds, until there was agreement on the 22 curricular milestones most related to the EPA. Table 1 lists the 22 milestones using an abbreviated nomenclature based on core competence and domain, for example, "effectively communicates with other caregivers during transitions of care" is an Interprofessional Communication (IPC) core competence of domain C and item 1 (C1) (Green, 2009). Using these 22 milestones, we created a Q-sort exercise to distribute and collect at an APDIM workshop. For the exercise we created cards with a curricular milestone on the front and an example of the milestones as it applies to the EPA on the back. In a similar iterative process, we also mapped curricular milestones to our individual curricula.

\section{Prioritizing Milestones}

We distributed the Q-sort exercise, a validated ranking process, for this EPA to participants at the APDIM workshop. Participants were IM program faculty who worked in groups of two to three, called participant units, to prioritize the milestones for the EPA. Participants were given instructions on 
113 how to rank the milestones by Q-sort methodology. Q-sort methodology enables researchers with some

114 limitation to study subjectivity using a combination of qualitative and quantitative methods (Kampen,

115 2013). It prioritizes the opinions of an observer (Brown, 1996) and provides an organized means of

116 identifying priorities and areas of divergent opinions within a group (Valenta, 1997). In a Q-sort, the

117 observer rank-orders a set of statements from most important to least important, using an inverted

118 quasi-normal distribution (Brown, 1996; van Exel, 2005). The sample of statements (the Q sample)

119 may represent an existing framework, in this case, the 22 milestones related to the EPA (Brown, 1996;

120 van Exel, 2005). Thus, the statements are the unit of analysis; the number of observers is less important

121 than is their theoretical relevance to the topic (Valenta, 2997). Once sorted, statements are analyzed by

122 rank category with a standard deviation. The Q-sort method uses a mathematical substructure to reveal

123 priorities of subjective viewpoints of the observers. The results of the Q-sort can be used to describe

124 the sample of viewpoints, in this case, in prioritization of milestones, rather than the sample of

125 observers (van Exel, 2005).

We analyzed the Q-sort results by calculating the mean rank order of milestones by faculty

127 units. With this mean ranking, we listed the milestones in order of priority. We identified the top 8

128 milestones because, by Q-sort methodology, the top 8 milestones confer those milestones more than

129 neutral status in the normal distribution. We calculated the proportion of milestones used of the total 22

130 milestones in the curriculum for each program. With each innovation we calculated the proportion of

131 milestones that were in the top 8 compared to the total. We then considered the milestones in common

132 between curricula both in the total 22 milestones and in the top 8 milestones to look for trends.

\section{Results}


First, we will describe the milestones as they were mapped to each transitions of care program.

136 Then, we will describe the Q-sort exercise results. Finally, we will reflect on our individual curricula 137 using the prioritized milestones as a standard for curriculum.

\section{Mapping Milestones}

In this section we will briefly describe the individual transitions of care curricula and the results

141 of mapping the milestones to each program.

Simulation

SIU is a small University program in Springfield, Illinois with one academic ambulatory site and two affiliate hospitals. During an Objective Structured Systems-Interaction Exam or simulation,

146 residents are observed discharging a patient from the hospital and evaluated on how well they

147 demonstrated the following observable behaviors: Use of the Situation, Background, Assessment, 148 Recommendation format to notify the Anti-Coagulation clinic of the patient's Warfarin levels and 149 dose, Use of Electronic Health Record to document medication changes, Use of the Hospital's 150 medication reconciliation form, and Legibility and Accuracy of written prescriptions. Five of the 22

151 curricular milestones are identified for the simulation curriculum: Patient Care (PC) C1, Synthesize all 152 available data; IPC A5, Utilize patient-centered education strategies; IPC F2, Ensure succinct, relevant, 153 and patient-specific written communication; Professionalism (P) A1, Document and report clinical 154 information truthfully; System-Based Practice (SBP) B1, Appreciate roles of a variety of health care 155 providers. 
Hennepin County Medical Center is a moderate-sized academic training program in

159

160

161

162

163

164

165

166

167

168

Minneapolis, Minnesota with one ambulatory clinic and one hospital affiliate. This innovation targets

the nine primary care track residents in the program. A discharge clinic feedback provides patients with pharmacist-assisted medication reconciliation, lab and radiology testing follow-up, and appointment confirmation. The resident evaluates the quality of the discharge and gives feedback to the ward team resident who discharged the patient. This evaluation includes direct feedback from the patient regarding the discharge processes as well as structured feedback on the written discharge summary. Nine of the 22 curricular milestones are identified for the discharge clinic feedback curriculum: SBP A2, Manage and coordinate care and care transitions across multiple delivery systems; IPC A5, Utilize patient-centered education strategies; IPC F2, Ensure succinct, relevant, and patient-specific written communication; PC F10, Customize care in the context of the patient's preferences and overall health; PC C3, Modify differential diagnosis and care plan based upon clinical course and data as appropriate; PC B2, Accurately track important changes in the physical examination; P D2, Carry out timely interactions with colleagues, patients and their designated caregivers; Problem-Based Learning and Improvement (PBLI) F1, Respond welcomingly and productively to feedback from all members of the health care team; PBLI A3, Reflect on audit compared with local or national benchmarks.

\section{Tracer}

Baystate Medical Center, Springfield, Massachusetts, is a moderate-sized, academic training program with one academic ambulatory site and one large hospital affiliate. In a two-week experiential block rotation, the TRAnsitions of Care Rotation (TRACER) resident follows the ward team patient into the Post-Acute Care (PAC) settings, including home, rehabilitation, and long-term care. Follow-up includes a visit to the patient in PAC and a formal assessment of the transition, using tools modified from the transition of care literature. These data are communicated in aggregate to the hospital PAC 
182 Performance Improvement team, to the ward team, at inter-professional attending rounds, and at 183 morning report. Seven curricular milestones are identified for the Tracer curriculum: IPC C1,

184 Effectively communicate with other caregivers during transitions of care; SBP A2, Manage and 185 coordinate care and care transitions across multiple delivery systems; IPC D3, Engage in collaborative 186 communication with all members of the health care team; IPC A5, Utilize patient-centered education 187 strategies; IPC F2, Ensure succinct, relevant, and patient-specific written communication; PC F10, 188 Customize care in the context of the patient's preferences and overall health; SBP B1, Appreciate roles 189 of a variety of health care providers.

\section{Prioritizing and Applying Milestones}

We collected 55 Q-sort rankings from faculty units at the APDIM workshop who ranked the 22

IM curricular milestones related to "a safe and effective discharge form the hospital." We report the prioritized milestones by Q-sort from the APDIM workshop (Table 1) on transitions of care. The priority range for the top 8 prioritized milestones is $4.2-5.7$ (SD $0.97-1.84$ ). From the total 22 milestones, the simulation innovation identified 5 of 22 milestones, discharge clinic 9 of 22 milestones, and tracer 7 of 22 milestones related to the EPA.

We considered two tiers of milestones. We emphasize the top 8 milestones in our analysis for reasons described in the methods. Milestones identified in each innovation related to one of the top 8 prioritized milestones $75 \%$ of the time; thus, more frequently than the milestones with lower priority.

201 Four of the top 8 milestones were shared by curricula. Two milestones are shared by all three curricula: IPC A5, Utilize patient-centered education and IPC F2, Ensure succinct, relevant, and patient-specific written communication. Two other milestones are shared by two curricula: SBP A2, Manage and coordinate care and care transitions across multiple delivery systems and PC F10, Customize care in 205 the context of the patient's preferences and overall health. Alternatively, few milestones are in the 
206 lower priority milestones set, and there is only 1 milestone shared by more than a single program in the

207 lower priority milestones, that is, SBP B1, Appreciate roles of a variety of health care providers,

208 including, but not limited to, consultants, therapists, nurses, home care workers, pharmacists, and

209 social workers. If you combine the three innovations, all of the top 8 milestones are included.

\section{Conclusion:}

In a learning community of innovative educators, we identified the transition of care curriculum as important, largely lacking, and challenging to develop. Three curricula mapped their individual

214 program innovations to the new assessment framework of milestones related to the EPA, "A safe and 215 effective discharge from the hospital." We found that the milestones in our individual curricula had a 216 strong correlation with higher prioritized milestones in the EPA. Given this correlation, prioritizing IM 217 curriculum milestones in an iterative process may have application in medical education curriculum 218 development, especially across programs.

A limitation of this collaboration is its retrospective look at innovation in a new framework.

221 The retrospective aspect is a historical phenomenon, that is, these curricula existed prior to the milestones framework. Although non-traditional, this retrospective look allows for an inquisitive matching of milestones across program innovation. Another limit is that the authors each rated the milestones associated with their own program without a peer or participant checker or a group vetting

226 the context of the milestones. This work is useful for future prospective work on educational 227 assessment of the Transition of Care. 
The transition of care remains a challenge to the patient, to the health care system, and to

230 training programs. Tools related to the assessment of "a safe and effective discharge from the hospital"

231 help narrow the current training gap. Programs may apply one or all of the transitions of care curricula

232 described. Alternatively, programs may consider applying the top 8 milestones defined by the

233 prioritization method, Q-sort, to an already existing program in transition of care; thereby, assessing

234 the relevance of their curriculum to a benchmark. Establishing a list of milestones for an EPA can

235 occur in siloes at each individual program or in collaborative groups. The Q-sort method may have a

236 role in the process as we develop standards for EPAs in medical education. Milestones are a new

237 training rubric for measurable outcomes and competency-based advancement. We need innovative

238 ways to apply milestones and EPAs to curricula (Hauer 2013). The milestones give us a context to

239 share individual innovations and to compare and contrast using a standardized frame. 


\section{Reference:}

244 Bray-Hall S, Schmidt K, Aagaard E. Toward safe hospital discharge: a transitions in care curriculum 245 for medical students. J Gen Intern Med. 2010 Aug;25(8):878-81.

246

247 Brown SR. Q Methodology and Qualitative Research. Qual Health Res. 1996; 6:561-567.

248

249 Coit MH, Katz JT, McMahon GT. The effect of workload reduction on the quality

250 of residents' discharge summaries. J Gen Intern Med. 2011 Jan;26(1):28-32.

251

252 Coleman EA, Berenson RA. Lost in transition: challenges and opportunities for

253 improving the quality of transitional care. Ann Intern Med. 2004 Oct

$254 \quad 5 ; 141(7): 533-6$.

255

256 Dinescu A, Fernandez H, Ross JS, Karani R. Audit and feedback: an intervention

257 to improve discharge summary completion. J Hosp Med. 2011 Jan;6(1):28-32.

258

259 Eskildsen MA. Review of Web-Based Module to Train and Assess Competency in

260 Systems-Based Practice. J Am Geriatr Soc. 2010 Dec;58(12):2412-3.

262 Forster AJ, Murff HJ, Peterson JF, Gandhi TK, Bates DW. The incidence and

263 severity of adverse events affecting patients after discharge from the hospital. Ann Intern Med. 2003

264 Feb 4;138(3):161-7. 
266 Green ML, Aagaard EM, Caverzagie KJ, Chick, DA, Holmboe E, Kane G, et al. Charting the Road to

267 Competence: Developmental Milestones for Internal Medicine Residency Training. J Grad Med Educ.

$2682009 ; 1: 5-20$.

269

270 Greysen SR, Schiliro D, Curry L, Bradley EH, Horwitz LI. "Learning by

271 doing"--resident perspectives on developing competency in high-quality discharge care. J Gen Intern

272 Med. 2012 Sep;27(9):1188-94.

273

274 Hauer KE, Kohlwes J, Cornett P, Hollander H, Ten Cate O, Ranji SR, Soni K, Iobst W, O'Sullivan P.

275 Identifying entrustable professional activities in internal medicine training. J Grad Med Educ. 2013

276 Mar;5(1):54-9.

277

278 Jencks SF, Williams MV, Coleman EA. Rehospitalizations among patients in the

279 Medicare fee-for-service program. N Engl J Med. 2009 Apr 2;360(14):1418-28.

280 Erratum in: N Engl J Med. 2011 Apr 21;364(16):1582.

281

282 Kampen, J; Tamas, P. "Overly ambitious: contributions and current status of Q methodology". Quality 283 and Quantity. November 2013

284

285 Kripalani S, LeFevre F, Phillips CO, Williams MV, Basaviah P, Baker DW.

286 Deficits in communication and information transfer between hospital-based and

287 primary care physicians: implications for patient safety and continuity of care. JAMA. 2007 Feb

$288 \quad 28 ; 297(8): 831-41$. 
290 Lai CJ, Nye HE, Bookwalter T, Kwan A, Hauer KE. Postdischarge follow-up visits

291 for medical and pharmacy students on an inpatient medicine clerkship. J Hosp Med.

2922008 Jan;3(1):20-7.

293

294 Legault K, Ostro J, Khalid Z, Wasi P, You JJ. Quality of discharge summaries

295 prepared by first year internal medicine residents. BMC Med Educ. 2012 Aug

$296 \quad 15 ; 12: 77$.

297

298 Meade LB, Caverzagie KJ, Swing SR, Jones RR, O'Malley CW, Yamazaki K, Zaas AK. Playing with 299 curricular milestones in the educational sandbox: Q-sort results from an internal medicine educational 300 collaborative. Acad Med. 2013 Aug;88(8):1142-8.

301

302 Meade LB, Walsh MM, and Todd CY. Workshop: "Lost or Found in Transition: Educational

303 Innovation for Transitions of Care” 16. APDIM Spring Meeting, Las Vegas. April 12-13, 2011.

304

305 Mohta N, Vaishnava P, Liang C, Ye K, Vitale M, Dalal A, Schnipper J. The

306 effects of a 'discharge time-out' on the quality of hospital discharge summaries.

307 BMJ Qual Saf. 2012 Oct;21(10):885-90.

308

309 Myers JS, Jaipaul CK, Kogan JR, Krekun S, Bellini LM, Shea JA. Are discharge

310 summaries teachable? The effects of a discharge summary curriculum on the quality

311 of discharge summaries in an internal medicine residency program. Acad Med. 2006

312 Oct;81(10 Suppl):S5-8. 
314 Nasca TJ, Philibert I, Brigham T, Flynn TC. The next GME accreditation

315 system--rationale and benefits. N Engl J Med. 2012 Mar 15;366(11):1051-6.

316

317 Schumacher DJ, Englander R, Carraccio C. Developing the master learner:

318 applying learning theory to the learner, the teacher, and the learningenvironment. Acad Med. 2013

319 Nov;88(11):1635-45.

320

321 Talwalkar JS, Ouellette JR, Alston S, Buller GK, Cottrell D, Genese T, Vaezy

322 A. A structured workshop to improve the quality of resident discharge summaries. J Grad Med Educ. 3232012 Mar;4(1):87-91.

324

325 ten Cate O, Scheele F. Competency-Based Postgraduate Training: Can We Bridge the Gap between

326 Theory and Clinical Practice? Acad Med. 2007; 82:542-547.

327

328

329

Valenta AL, Wigger U. Q-methodology: definition and application in health care informatics. J Am Med Inform Assoc. Nov-Dec 1997;4(6):501-510.

330

331

332

van Exel J, deGraaf G. Q methodology: a sneak preview. 2005; http://www.qmethodology.net/. Accessed March 29, 2011.

334 van Walraven C, Seth R, Austin PC, Laupacis A. Effect of discharge summary 
335 availability during post-discharge visits on hospital readmission. J Gen Intern Med. 2002

336 Mar;17(3):186-92. 


\section{Table $\mathbf{1}_{\text {(on next page) }}$}

Table 1: Milestones for the EPA "A safe and effective discharge"

Table 1 lists the 22 Internal Medicine Curricular milestones by category competency/domain (A); the Q-sort priority for the milestones (B) from highest to lowest with 7, the highest priority and 1 , the lowest priority; the standard deviation of prioritization (C); the milestones descriptor (D), the transition of care example for that milestone (E) and an $X$ to denote if this milestones was present in the top 8 milestones (F), Simulation (S), Discharge clinic feedback (DCF), Tracer (T). Abbreviations: Interpersonal communication ( IPC), Systems based practice (SBP) , Patient care (PC), Professionalism (P) , Medical knowledge (MK), Problem based learning and improvement (PBLI). 
Table 1: Milestones for the EPA "A safe and effective discharge"

\begin{tabular}{|c|c|c|c|c|c|c|c|c|}
\hline & Priority & SD & Milesotnes Abbreviated & Example & $\begin{array}{l}\text { Top 8 } \\
\text { Q-sort }\end{array}$ & S & DCF & $\mathrm{T}$ \\
\hline $\begin{array}{l}\mathrm{IPC} \\
\mathrm{C} 1^{*}\end{array}$ & 5.78 & 0.97 & $\begin{array}{l}\text { Effectively communicate with other } \\
\text { caregivers during transitions of care }\end{array}$ & $\begin{array}{l}\text { Communicates with the PCP } \\
\text { or nursing home at discharge. }\end{array}$ & $\mathbf{X}$ & & & $\mathbf{x}$ \\
\hline $\begin{array}{l}\text { SBP } \\
\text { A2 }\end{array}$ & 5.52 & 1.16 & $\begin{array}{l}\text { Manage and coordinate care and } \\
\text { care transitions across multiple } \\
\text { delivery systems. }\end{array}$ & $\begin{array}{l}\text { Works with the case manager } \\
\text { to make appropriate decisions } \\
\text { about where a patient should } \\
\text { go after discharge ie home } \\
\text { with nursing services or to a } \\
\text { nursing home. }\end{array}$ & $\mathbf{X}$ & & $\mathbf{x}$ & $\mathbf{x}$ \\
\hline $\begin{array}{l}\mathrm{PC} \\
\mathrm{C} 1\end{array}$ & 4.89 & 1.25 & Synthesize all available data & $\begin{array}{l}\text { Able to synthesize a } \\
\text { complicated hospital course. }\end{array}$ & $\mathbf{X}$ & $\mathbf{X}$ & & \\
\hline $\begin{array}{l}\text { IPC } \\
\text { D3 }\end{array}$ & 4.74 & 1.35 & $\begin{array}{l}\text { Engage in collaborative } \\
\text { communication with all members of } \\
\text { the health care team }\end{array}$ & $\begin{array}{l}\text { Seeks out the nurse and case } \\
\text { manager about the plan for } \\
\text { discharge. }\end{array}$ & $\mathbf{x}$ & & & $\mathbf{x}$ \\
\hline $\begin{array}{l}\text { IPC } \\
\text { A5 }\end{array}$ & 4.56 & 1.63 & $\begin{array}{l}\text { Utilize patient-centered education } \\
\text { strategies }\end{array}$ & $\begin{array}{l}\text { Explains the primary diagnosis } \\
\text { to the patient at discharge and } \\
\text { uses teach back to check for } \\
\text { understanding. }\end{array}$ & $\mathbf{X}$ & $\mathbf{X}$ & $\mathbf{X}$ & $\mathbf{x}$ \\
\hline $\begin{array}{l}\text { IPC } \\
\text { F2 }\end{array}$ & 4.48 & 1.31 & $\begin{array}{l}\text { Ensure succinct, relevant, and } \\
\text { patient-specific written } \\
\text { communication }\end{array}$ & $\begin{array}{l}\text { A succinct discharge summary } \\
\text { with key components. }\end{array}$ & $\mathbf{X}$ & $\mathbf{X}$ & $\mathbf{X}$ & $\mathbf{X}$ \\
\hline P A1 & 4.48 & 1.85 & $\begin{array}{l}\text { Document and report clinical } \\
\text { information truthfully }\end{array}$ & $\begin{array}{l}\text { Really did call the pharmacy to } \\
\text { confirm the medication list if } \\
\text { they say they have. }\end{array}$ & $\mathbf{X}$ & $\mathbf{X}$ & & \\
\hline $\begin{array}{l}\text { PC } \\
\text { F10 }\end{array}$ & 4.26 & 1.20 & $\begin{array}{l}\text { Customize care in the context of the } \\
\text { patient's preferences and overall } \\
\text { health }\end{array}$ & $\begin{array}{l}\text { Offers home care or nursing } \\
\text { home care depending on } \\
\text { patient preferences. }\end{array}$ & $\mathbf{X}$ & & $\mathbf{X}$ & $\mathbf{X}$ \\
\hline $\begin{array}{l}\mathrm{PC} \\
\mathrm{C} 3\end{array}$ & 4.15 & 1.17 & $\begin{array}{l}\text { Modify differential diagnosis and } \\
\text { care plan based upon clinical } \\
\text { course and data as appropriate }\end{array}$ & $\begin{array}{l}\text { If the patient is admitted with } \\
\text { presumed pnemonia but the } \\
\text { clinical course is consistent } \\
\text { with CHF then this resident } \\
\text { identifies CHF as the final } \\
\text { diagnosis and is able to } \\
\text { explain why it is not } \\
\text { pneumonia. }\end{array}$ & & & $\mathbf{X}$ & \\
\hline $\mathrm{P}$ i1 & 4.15 & 1.29 & $\begin{array}{l}\text { Treat patients with dignity, civility } \\
\text { and respect, regardless of race, } \\
\text { culture, gender, ethnicity, age or } \\
\text { socioeconomic status }\end{array}$ & $\begin{array}{l}\text { Makes special } \\
\text { accommodations for a } \\
\text { homeless patient such as } \\
\text { having social work assist with } \\
\text { clothing, food and/or shelter. }\end{array}$ & & & & \\
\hline $\begin{array}{l}\mathrm{PC} \\
\mathrm{B} 2\end{array}$ & 3.96 & 1.22 & $\begin{array}{l}\text { Accurately track important changes } \\
\text { in the physical examination }\end{array}$ & $\begin{array}{l}\text { Documents the mental status } \\
\text { physical exam upon discharge } \\
\text { for a patient admitted with } \\
\text { altered mental status. }\end{array}$ & & & $\mathbf{x}$ & \\
\hline
\end{tabular}


3 Table 1: Milestones for the EPA "A safe and effective discharge" (continued)

\begin{tabular}{|c|c|c|c|c|c|c|c|c|}
\hline & Priority & SD & Milesotnes Abbreviated & Example & $\begin{array}{l}\text { Top 8 } \\
\text { Q-sort }\end{array}$ & $S$ & DCF & $\mathrm{T}$ \\
\hline $\begin{array}{l}\mathrm{PC} \\
\mathrm{A} 2\end{array}$ & 3.93 & 1.17 & $\begin{array}{l}\text { Seek and obtain appropriate, } \\
\text { verified, and prioritized data from } \\
\text { secondary sources }\end{array}$ & $\begin{array}{l}\text { Verifies the medication list with } \\
\text { the pharmacy or PCP. }\end{array}$ & & & & \\
\hline P D2 & 3.74 & 1.16 & $\begin{array}{l}\text { Carry out timely interactions with } \\
\text { colleagues, patients and their } \\
\text { designated caregivers }\end{array}$ & $\begin{array}{l}\text { Completes the discharge } \\
\text { summary within } 24 \text { hours of } \\
\text { discharge. }\end{array}$ & & & $x$ & \\
\hline $\begin{array}{l}\text { MK } \\
\text { A9 }\end{array}$ & 3.70 & 1.14 & $\begin{array}{l}\text { Demonstrate sufficient knowledge } \\
\text { of socio-behavioral sciences }\end{array}$ & $\begin{array}{l}\text { Has the knowledge that a } \\
\text { patient without health } \\
\text { insurance may have many } \\
\text { barriers to transition of care } \\
\text { such as cost of medications, } \\
\text { access to PCP, and poor } \\
\text { health literacy. }\end{array}$ & & & & \\
\hline $\begin{array}{l}\text { IPC } \\
\text { A4 }\end{array}$ & 3.70 & 1.27 & $\begin{array}{l}\text { Engage patients/advocates in } \\
\text { shared decision-making for } \\
\text { uncomplicated diagnostic and } \\
\text { therapeutic scenarios }\end{array}$ & $\begin{array}{l}\text { Checks with the patient about } \\
\text { the convenience of the follow } \\
\text { up appointment. }\end{array}$ & & & & \\
\hline $\begin{array}{l}\text { SBP } \\
\text { B1 }\end{array}$ & 3.58 & 1.30 & $\begin{array}{l}\text { Appreciate roles of a variety of } \\
\text { health care providers }\end{array}$ & $\begin{array}{l}\text { Uses the home nurse for to } \\
\text { assist with education of the } \\
\text { primary diagnosis and } \\
\text { medication reconciliation after } \\
\text { discharge. }\end{array}$ & & $X$ & & $x$ \\
\hline $\begin{array}{l}\text { PBLI } \\
\text { F1 }\end{array}$ & 3.50 & 1.17 & $\begin{array}{l}\text { Respond welcomingly and } \\
\text { productively to feedback from all } \\
\text { members of the health care team }\end{array}$ & $\begin{array}{l}\text { Responds to nursing concerns } \\
\text { about readiness for discharge. }\end{array}$ & & & $x$ & \\
\hline $\begin{array}{l}\text { IPC } \\
\text { E3 }\end{array}$ & 3.50 & 1.21 & $\begin{array}{l}\text { Communicate consultative } \\
\text { recommendations to the referring } \\
\text { team in an effective manner }\end{array}$ & $\begin{array}{l}\text { Includes the name and } \\
\text { recommendations of a } \\
\text { consultant in the discharge } \\
\text { summary. }\end{array}$ & & & & \\
\hline $\begin{array}{l}\text { SBP } \\
\text { E3 }\end{array}$ & 3.41 & 1.47 & $\begin{array}{l}\text { Demonstrate the incorporation of } \\
\text { cost-awareness principles }\end{array}$ & $\begin{array}{l}\text { Uses the antibiotic that is most } \\
\text { appropriate but also affordable } \\
\text { to the outpatient at discharge. }\end{array}$ & & & & \\
\hline P J1 & 3.11 & 1.45 & Maintain patient confidentiality & $\begin{array}{l}\text { Knows to get permission from } \\
\text { the patient or their health care } \\
\text { proxy to disclose any medical } \\
\text { information. }\end{array}$ & & & & \\
\hline P F7 & 2.54 & 1.27 & $\begin{array}{l}\text { Recognize the need to assist } \\
\text { colleagues in the provision of duties }\end{array}$ & $\begin{array}{l}\text { A supervising resident who } \\
\text { does a discharge for an intern } \\
\text { because it is too complex for } \\
\text { that intern. }\end{array}$ & & & & \\
\hline $\begin{array}{l}\text { PBLI } \\
\text { A3 }\end{array}$ & 2.41 & 1.12 & $\begin{array}{l}\text { Reflect on audit compared with } \\
\text { local or national benchmarks }\end{array}$ & $\begin{array}{l}\text { Is aware of the high risk } \\
\text { concerns for re-admission. }\end{array}$ & & & $X$ & \\
\hline
\end{tabular}

6 Table 1 lists the 22 Internal Medicine Curricular milestones by category competency/domain (A); the Q-sort

7 priority for the milestones (B) from highest to lowest with 7, the highest priority and 1, the lowest priority; the

8 standard deviation of prioritization (C); the milestones descriptor (D), the transition of care example for that 
9 milestone (E) and an $\mathrm{X}$ to denote if this milestones was present in the top 8 milestones (F), Simulation (S), 10 Discharge clinic feedback (DCF), Tracer (T). Abbreviations: Interpersonal communication ( IPC), Systems 11 based practice (SBP), Patient care (PC), Professionalism (P), Medical knowledge (MK), Problem based 12 learning and improvement (PBLI). 